\title{
Assessing Leadership Practices, Organizational Climate and Its Effect towards Innovative Work Behaviour in R\&D
}

\author{
Haris M. Noor and Bari'ah Dzulkifli
}

\begin{abstract}
Achieving innovative organization has been the utmost agenda in every business operations recently. Thus, there is a need for a greater understanding of the leadership and organizational climate effect towards innovative work behaviour in work settings, particularly in $R \& D$ which involves creativity and innovation activities. The aim of this paper is to explore the relationship between leadership practice and organizational climate effect and its mediating effect towards innovative work behaviour. Data from 125 R\&D scientists of public agricultural agencies were used to assess leadership practices of their superiors, organizational climate and their innovative work behavior. Results suggested there was a significant relationship between organizational climate and innovative work behavior. This finding would enrich the previous studies across samples, criteria and settings. Implications of these findings are discussed.
\end{abstract}

Index Terms - Innovative work behaviour, leadership practice and organizational climate.

\section{INTRODUCTION}

Innovation and creative capacity are essential determinants of economic prosperity in a globalising and knowledge-based economy [1] . Moreover, it is believed as a major source of competitive advantage and being a key factor of achieving high productivity that would induce economic growth. Hence, the productivity will be able to assists improvising society [2], [3]. The organisations can become more innovative by capitalising the employees' ability to innovate. The abilities of capitalizing at individual level must be supported by the management system [4], [5]

There are numerous empirical studies that has proven that organisational climate is one of the factor to capitalise the employees' innovative work behaviour [4], [6]. Believing that organizational climate as a determinant factor to generate desired behaviour, there were studies conducted that insist to promote leadership as an antecedent of innovative work behaviour [7]-[9]

However, the influence of social environment as factors to innovative work behaviour remains unclear, and only few studies conducted to examine such behaviour in non western country [10]. According to Ismail [11], there are critical needs for more studies to be conducted linking organisational

Manuscript received November 15, 2012; revised January 15, 2013. This work was supported in part by the Post-graduate Centre and Research, Innovation, Commercialize and Consultancy Office (ORICC) of Universiti Tun Hussein Onn Malaysia. The author would like to thank Prof. T. Amabile for her permission to use KEYS instrument as a measure of Organizational climate.

The authors are with the Faculty of Technology Management and Business, Universiti Tun Hussein Onn Malaysia (e-mail: harisn@uthm.edu.my, bariahdzulkifli@yahoo.com). climate factor in analysing their influences on innovation within the Malaysian context.

Given that vast amount of money invested by the government of Malaysia on education and training in the last fifty years, the shortage of highly skilled and quality talents remains apparent. For this reason, Malaysia needs professionals with the requisite skills and expertise to add to the critical mass of the nation's talent and to strengthen the human resources including public agricultural R\&D agencies in order to anticipate more productive and innovative workers [12]

Throughout the endeavors taken by government, agricultural sector in Malaysia still facing the challenge of high bill imported food, un-economic production cost besides climate factor [12]-[14]. Hence this study attempted to analyse the organizational climate in agricultural sector and its mediating effect between leadership practice and innovative work behaviour.

\section{EMPIRICAL STUDIES}

\section{A. Relationship between Leadership Practices and Innovative Work Behaviour}

The determining factors in organizational innovation are affected by individual characteristics, such as leadership, resistance to change or the innovation support roles [5]. Most of the researchers deductively agreed that leadership can stimulate innovative work behaviour [15], [16]. Janssen [17] found evidence that employees responded more innovatively to higher level of job demands when they perceived that their efforts were fairly rewarded by their leader. The reward itself can promote intrinsic motivation of the employees. However, the author found that, although the behaviour of giving rewards to the employees was found to be related to innovativeness [15], [18], [19], Sanders [20] have proven vice versa; rewarding has no positive correlation with innovativeness.

According to Amabile [21], modeling behaviour has been linked to creativity. Accordingly, there also a number of studies have attempted to capture aspects of leader behaviours that encourage creativity of employees and eventually proven the relationship [22]-[24]. This is aligned with studies conducted by [15] who evidentially found "Model the way" as the new model of five exemplary leadership practices. Studies have also considered the relevance of leader support directly linked to "work ideas", or the actual innovative activities in which employees engaged in relation to employee creative performance [25]-[27].

- $H_{1}$ : Leadership Practices has positive relationship with innovative work behavior. 


\section{B. Relationship between Leadership Practices and Organizational Climate}

Leadership practices are set of behaviour that is applicable for anyone [15], [34]. Several research studies have proven that leadership has positive correlation with organisational climate [16], [22], [23], [31] [10], [15]-[17]. However, in these studies, the author found that the researchers were using different variables of leadership to test the relationship with organisational climate. According to Akkermans et.al, they have found that leadership behaviours have positive relationship with organisational climate. Akkermans and his colleagues listed eight variables of leadership behaviours; (controlling resource availability, delivering creativity \& innovation training, fostering new ways to do thing, providing structure, sharing information approaching mistakes \& failures, including others in decision making and focusing priorities).

While other researchers, De Jong, et al., [23], were using thirteen inventories of Yukl taxonomies [35], [36] of leadership behaviour to test the relationship and prove there are positive correlation. There are evidence showing authentic leadership contributes to a more positive work climate in the organisation as well [37]

Although there are differences of using different variables to test the relationship, both of these studies affirmed the appropriate leader's behaviours could stimulate the environment of innovation within the organisation. Therefore, next hypothesis can be formulated as below:

- $\mathrm{H}_{2}$ : Leadership Practices has positive relationship with organizational climate.

\section{Relationship between Organizational Climate and Innovative Work Behaviour}

De Jong and Den Hartog [26] have found the innovative work behaviour can be influenced by organization environment instead of just leadership. According to Hunter, et.al[9] although a variety of environmental variables have been identified that might influence creativity and innovation, many scholars stress the importance of climate to produce the relevant outcomes [8], [39]-[41]. Although there was a research that supports climate for innovation was not significant [42], most of the findings reported the significant positive relationship [43], [44]. That was because the organisational climate itself can designate the individuals, it is believed to increase intrinsic motivation of the employees [18], [26], [45], [46] According to Hassandra et.al [47], intrinsic motivation relates to the pleasure perception of doing behaviour. Meanwhile, intrinsic motivation is believed to be the most crucial factor to develop innovative work behaviour within employees [8], [48], [49] Thus, third hypothesis can be constructed as below:

- $H_{3}$ : Organisational climate has positive relationship with innovative work behavior.

\section{THEORETICAL FRAMEWORK}

Based on the literature discussed before, the above diagram demonstrated the relationship of the variables. (See Fig. 1)

- $H_{1}$ : Leadership practices will be positively related to employees' innovative behavior.
- $H_{2}$ : Leadership practices will be positively related to organizational climate.

- $H_{3}$ : Organizational climate will positively related to employees' innovative behavior.

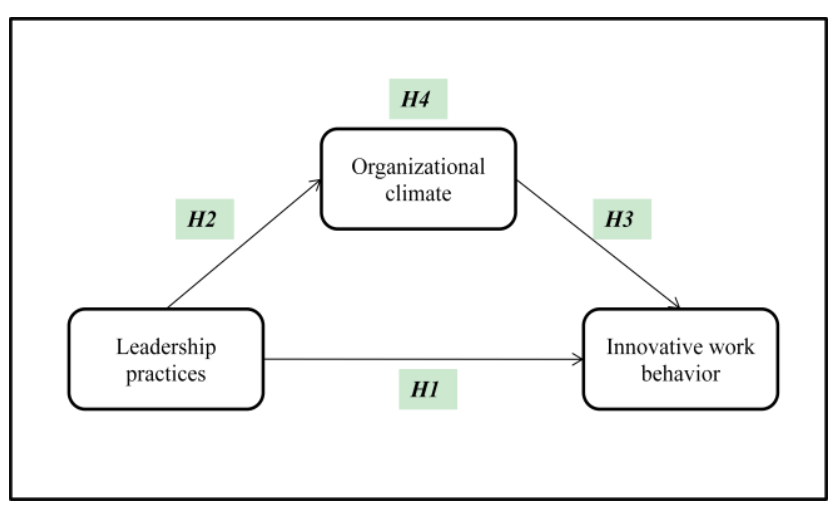

Fig. 1. Based on the literature discussed before, the above diagram demonstrated the relationship of the variables

\section{Methodology}

\section{A. Participants and Procedures}

Data were collected via questionnaires through purposive sampling method. The researchers contacted all eight public agricultural R\&D agencies based on Agricultural Science and Technology Indicators [50]. Finally, seven out of the eight agencies agreed to cooperate.

Questionnaires were sent out to scientists and assistant scientists within the seven major agencies; forestry, veterinary institute, cocoa, palm oil, agricultural R\&D institute, nuclear and fishery. Respondents were assured of the confidentiality of all answers. The questionnaires were personally administered to all the individuals employed in these agencies. The rest was distributed by email. Out of 250 questionnaires that were distributed, 150 (60 per cent response rate) were returned.

\section{B. Instruments and Reliability Test}

The instrument employed to measure organisational climate comprised of 50 items and was developed by Amabile [48]. The instrument covers a total of 3 sub dimensions of work environment which is Management Practice, Organisational Motivation and Resources. Meanwhile, the sub dimensions for Management Practice comprised of freedom, challenging work, managerial encouragement, and work group support.

For Organisational Motivation dimension comprised of organisational encouragement and lack of organisational impediments. Sufficient resources and realistic workload pressure lied under Resources dimension. Individuals were asked to assess the extent to which each one of the 50 items applied to the agricultural agencies they were employed in. They have been asked to rate the organisational climate with a five-point Likert scale, ranging from 1 (never) to 5 (very frequently). The overall Cronbach's $\alpha$ for the organisational climate scale was 0.93 . Meanwhile Cronbach's $\alpha$ for each dimensions underlying on organisational climate were as following; Management practice, 0.889; Organizational motivation, 0.857 and Resources, 0.854 .

To measure the leadership practices of an organisation, the 
authors have used Kouzes \& Posner [51] Leadership Practices Inventory with reliability test 0.971 . The inventory has 5 dimensions namely; Model the way, Inspire a shared vision, Challenge the process, Enable others to act, and Encourage the heart. Cronbach's $\alpha$ for each dimension is as follows; 0.891, 0.905, 0.849, 0.907 and 0.892 .

The instrument to measure the innovative work behaviour was developed by De Jong [28](2006) which has 15 items. The Cronbach's $\alpha$ for innovative work behaviour was 0.928 with 5 points Likert scale ranging from 1 (never) to 5 (very frequently) as well.

\section{RESULTS}

\section{A. Profile of the Respondent}

TABLE I: RESPONDENTS' PROFILE

\begin{tabular}{lccc} 
Demography & Category & Quantity & $\%$ \\
\hline \multirow{2}{*}{ Gender } & Male & 63 & 42.3 \\
& Female & 86 & 57.7 \\
\hline \multirow{2}{*}{ Age } & $<35$ & 79 & 52.7 \\
& $36-45$ & 36 & 24 \\
& $46-55$ & 29 & 19.3 \\
Education & $>56$ & 6 & 4.0 \\
background & Postgraduate & 85 & 57 \\
& Degree & 50 & 33.6 \\
\hline & Undergraduate & 14 & 9.4 \\
\hline $\begin{array}{l}\text { Years of } \\
\text { Service }\end{array}$ & 65 Years & 50 & 33.3 \\
& $>11$ Years & 56 & 28.7 \\
\hline \hline
\end{tabular}

The Table I above shows that female respondent is much higher that male $(57.7$ per cent). The corresponding respondents also perceived high education level by $57 \%$ which shows that pursuing studies and gaining knowledge are required for scientists to involve in their jobs expertise. Meanwhile, it can be concluded that years of service is fairly distributed among the categories.

\section{B. Correlation Analysis}

TABLE II: CORRELATION ANALYSIS

\begin{tabular}{lccccc}
\multicolumn{1}{c}{ Variable } & Mean & SD & I & II & III \\
\hline $\begin{array}{l}\text { I. Leadership } \\
\text { practice }\end{array}$ & 3.73 & 0.372 & & & \\
$\begin{array}{l}\text { II. Organizational } \\
\text { climate (OC) }\end{array}$ & 3.46 & 0.325 & $0.303 * *$ & & \\
$\begin{array}{l}\text { III. Innovative work } \\
\text { behaviour }\end{array}$ & 3.68 & 0.48 & 0.16 & $0.451 * *$ & $0.411^{* *}$ \\
\hline \hline Note: $* p<0.05, * * p<0.01$ & & & &
\end{tabular}

Table II showed the means, standard deviation, and correlations among the variables including the dimensions of Organisational climate. The outcome of the correlation of Leadership practices has no positive relationship towards innovative work behaviour Thus $H 1$ is rejected.

Meanwhile, Leadership practices proved that it has positive relationship with organizational climate $(r=0.303$, $p<0.01)$ although the correlational strength is quite low according to Guildford's rule of thumbs. Therefore, $\mathrm{H} 2$ is accepted. This study also confirmed that Organisational climate has positive relationship with innovative work behaviour $(r=0.451, p<0.01)$. The relationship shows moderate correlational strength. Hence, H3 is accepted.

\section{Regression Analysis}

TABLE III: REGRESSION ANALYSIS OF VARIABLES

\begin{tabular}{|c|c|c|c|c|c|c|c|}
\hline DV & IV & $R^{2}$ & $F$ & $B$ & $S E$ & $\beta$ & $t$ \\
\hline \multirow[b]{2}{*}{$X I$} & Constant & 0.026 & & 2.978 & 0.394 & & $7.551^{* 8}$ \\
\hline & $\begin{array}{l}\text { Leadership } \\
\text { Practices }\end{array}$ & & 3.223 & 0.189 & 0.105 & 0.16 & 1.795 \\
\hline \multirow[b]{2}{*}{$X 2$} & Constant & 0.092 & & 2.471 & 0.281 & & \\
\hline & $\begin{array}{l}\text { Leadership } \\
\text { Practices }\end{array}$ & & $12.393^{*}$ & 0.264 & 0.075 & 0.303 & $3.274^{*}$ \\
\hline \multirow[b]{2}{*}{$X I$} & Constant & 0.203 & & 1.572 & 0.378 & & $4.155^{* *}$ \\
\hline & $\begin{array}{l}\text { Organizational } \\
\text { climate }\end{array}$ & & $31.391^{* *}$ & 0.611 & 0.109 & 0.451 & $5.603^{* *}$ \\
\hline
\end{tabular}

Notes: $* p<0.05, * * p<0.01$

Notes: $X 1=$ Innovative work behaviour, $X 2=$ Organizational climate

The regression analysis started with innovative work behaviour as the dependent variable. Table III, shows that leadership practices explains 2.6 per cent of the variance $\left(R^{2}=0.026\right)$. The results of multiple regressions in the Table III shows that leadership practices model have no significant positive impact on innovative work behaviour with $(F=3.223$, $p>0.05)$. Meanwhile, the result shows a significant positive impact between leadership practices and organizational climate with $(F=12.393, p<0.05)$. The value of $R^{2}$ indicates only 9.2 per cent variance is explained by leadership practices in organizational climate. The model of the third regression concerning the innovative work behaviour indicates that organizational climate is a good predictor of innovative work behaviour $(\beta=0.451, t=5.603, p<0.01)$ with the explanation value of 20.3 per cent on innovative work behaviour

\section{DISCUSSION AND CONCLUSION}

Proliferations of studies have been embarked to examine the relationship of leadership and its effect on employees' behaviour. The studies showed that leadership can be an effective tool to obtain relevant outcomes [33]. Instead of influencing the relevant outcomes, leaders also play a critical role to shape organisational climate [52].

This research gives the outcome of analysis to examine the relationship between leadership practices and innovative work behaviour outcomes. However, one of the hypotheses (H1) was not supported as it is found to be insignificant although most of the literature reports positive significant relationship among the variables. The insignificant result in this study might be due to the job nature of $R \& D$ setting in Malaysian context. The job nature of scientists required them to work independently without involving with top management. This means that top management have placed much trust to the employees. According to [32] Imran et al., (2011), the attempted studies on examining relationship between leadership show inconsistent findings which can be 
varied by many factors.

Ironically, the rest of hypotheses tested have shown encouraging result. Leadership practices have significant relationship with organisational climate thus supporting the hypothesis $(H 2)$. The result is aligned with literature before this [9], [39], [40], [53].

As the organizational climate itself can enhance creativity among the employees, the literature found there is significant effect on innovative work behaviour which has been proven in this study. H3 is again supported. The finding which shows no relationship between organisational climate and innovative work behaviour might be due to the size of the organisation which posses strong leadership practice in the organisation rather than in large organisation [29]. In this case, public agricultural $R \& D$ agencies are considered as a large organisation which employed thousand of scientists.

Furthermore, the outcome of this study provides external validity to the social psychology which has been developed in Western country but can be employed in Malaysian sample. Therefore, it would enrich findings of organisational climate as effective predictors of innovative behaviour across criteria, samples and settings [9].

\section{IMPLICATION}

This research indeed has theoretical and practical implications. Through the theoretical perspective, present research contributes a momentous proven theory in existing body of knowledge in the field of predicting innovative work behaviour. That was because little attention has been made to explore the impact of leadership practice towards creating the right climate in order to cultivate innovative work behaviour. This research also provides a guideline for top management to set the right climate for their workers. Consequently the right climate would boost up the intrinsic motivation among the workers to become more innovative. Although the results demonstrated non significant effect on the link of leadership practice and innovative work behaviour, there is evidence that leadership practice has positive relationship with organizational climate. Moreover, there is mediating effect between leadership practice and innovative work behaviour. In reality, the non significant finding might be due to the size and hierarchy of position in an organization. Further investigation should be made to analyse the factors affecting the relationship.

\section{REFERENCES}

[1] M. S. Gertler and D. A. Wolfe, "Spaces of knowledge flows. Clusters in a global context," in Clusters and Regional Development: Critical Reflections and Explorations, P. Cooke, R. Martin, and B. T. Asheim, Eds. London: Routledge, 2006.

[2] A. H. V. D. Ven, "Central Problems in the Management of innovation," Management Science, vol. 32, no. 2, pp. 590-607, 1986.

[3] C. H. M. Ketels, "Michael Porter's Competitiveness Framework-Recent Learnings and New Research Priorities," Journal of Industry, Competition and Trade, vol. 6, no. 2, pp. 115-136, Oct. 2006.

[4] C. Andriopoulos, "Determinants of organisational creativity: a literature review," Management Decision, vol. 39, no. 10, pp. 834-840, 1998.

[5] F. J. L. Montes, A. R. Moreno, and L. M. M. Fernández, “Assessing the organizational climate and contractual relationship for perceptions of support for innovation," International Journal of Manpower, vol. 25, no. 2, pp. 167-180, 2004

[6] R. Imran, T. Saeed, and A. Fatima, "Organizational climate as a predictor of innovative work behavior," vol. 4, no. 15, pp. 3337-3343, 2010 .

[7] A. Carmeli, R. Meitar, and J. Weisberg, "Self-leadership skills and innovative behavior at work," International Journal of Manpower, vol. 27 , no. 1 , pp. 75-90, 2006.

[8] M. G. Patterson, M. A. West, V. J. Shackleton, J. F. Dawson, R. Lawthom, S. Maitlis, D. L. Robinson, and A. M. Wallace, "Validating the organizational climate measure: links to managerial practices, productivity and innovation," Journal of Organizational Behavior, vol. 26, no. 4, pp. 379-408, Jun. 2005.

[9] S. T. Hunter, K. E. Bedell, and M. D. Mumford, "Climate for Creativity: A Quantitative Review," vol. 19, no. 1, pp. 69-90, 2007.

[10] M. L. A. Hsu and H. Fan, "Organizational Innovation Climate and Creative Outcomes: Exploring the Moderating Effect of Time Pressure," vol. 22, no. 4, pp. 378-386, 2010.

[11] M. Ismail, "Creative Climate and Learning culture: Their Contributions towards Innovation within a Property Developer Organization- A Review," pp. 22-28, 2006.

[12] MOSTI Facts and Figure, 2008.

[13] "Malaysia import makanan RM221.81b," Utusan Malaysia, pp. 15, Jun-2012.

[14] A. Asmawi and A. V. Mohan, "Understanding patterns of organizational culture: A study in Malaysian R\&D institutions," in 2010 IEEE International Conference on Management of Innovation \& Technology, 2010, pp. 324-329.

[15] J. M. Kouzes and B. Z. Posner, The Leadership Challenges, San Franchisco: Jossey-Bass Publishers, 2002.

[16] I. C. Robledo, D. R. Peterson, and M. D. Mumford, "Leadership of scientists and engineers: A three-vector model," Journal of Organizational Behavior, November, 2010.

[17] O. Janssen, "Job demands, Perceptions of Effort- Reward Fairness and Innovative Work Behaviour," Journal of Occupational and Organizational Psychology, vol. 73, pp. 287-302, 2000.

[18] E. Ayranci, "A Research on the Relationship between Leadership Orientations and the Innovativeness of Owner-Managers in Turkish Businesses," Journal of Management and Strategy, vol. 2, no. 1, pp. 48-59, Mar. 2011

[19] L. Gumusluog and A. Ilsev, "Transformational Leadership and Organizational Innovation: The Roles of Internal and External Support for Innovation," vol. 90, no. 312, pp. 264-277, 2009.

[20] K. Sanders, "How to Support Innovative Behaviour?The Role of LMX and Satisfaction with HR Practices," Technology and Investment, vol. 01, no. 01, pp. 59-68, 2010.

[21] T. M. Amabile, S. G. Barsade, J. S. Mueller, and B. M. Staw, "Work," Administrative Science Quarterly, no. 50, pp. 367-403, 2005.

[22] H. J. L. Akkermans, S. G. Isaksen, and E. J. Isaksen, "Leadership For Innovation: A Global Climate Survey,” A Cru Technical Report, 2008.

[23] J. P. J. D. Jong and D. N. D. Hartog, "How leaders influence employees' innovative behaviour," European Journal of Innovation Management, vol. 10, no. 1, pp. 41-64, 2007.

[24] P. Tierney, "Leadership and Employee Creativity in Handbook of Organizational Creativity," in Leadership and Employee Creativity in Handbook of Organizational Creativity, J. Zhou and C. Shalley, Eds. United States: Lawrence Erlbaum Associates, 2008.

[25] J. D. Jong and D. D. Hartog, "Measuring Innovative Work Behaviour," Creativity and Innovation Management, vol. 19, no. 1, pp. 23-36, Mar. 2010.

[26] J. D. Jong and D. D. Hartog, Leadership as a Determinant of Innovative Behaviour A Conceptual Framework, June. 2003.

[27] F. Gil, R. Ramon, C. M. Alcover, and B. Angel, "satisfaction and performance in work groups Effects of team climate and group potency," Journal of Managerial Psychology, vol. 20, no. 3-4, pp. 312-328, 2005.

[28] D. N. D. Hartog and J. D. Jong, "Innovative Work Behavior: Measurement and Validation," Working paper, no. November. pp. 2-27, 2008.

[29] R. Khan, A. U. Rehman, and A. Fatima, "Transformational leadership and organizational innovation: Moderated by organizational size," vol. 3, no. 11, pp. 678-684, 2009.

[30] Z. Lei and F. Zhou, "Leadership Style and Employee Innovative Behavior: the Mediating Effects of Psychological Empowerment," no. 2010, pp. 26-29, 2011.

[31] V. J. G. Morales, F. M. Reche, and N. H. Torres, "Influence of transformational leadership on organizational innovation and performance depending on the level of organizational learning in the pharmaceutical sector," Journal of Organizational Change Management, vol. 21, no. 2, pp. 188-212, 2008. 
[32] R. Imran and M. A. Haque, "Mediating Effect of Organizational Climate between Transformational Leadership and Innovative Work Behaviour," vol. 26, no. 2, pp. 183-199, 2011.

[33] P. Tierney, S. M. Farmer, and G. B. Graen, "An Examination of Leadership and Employee Creativity: The Relevance of Traits and Relationships," Personnel Psychology, vol. 52, pp. 591-620, 1999.

[34] J. Rank, N. E. Nelson, T. D. Allen, and X. Xu, "Leadership predictors of innovation and task performance: Subordinates' self-esteenn and self-presentation as moderators," pp. 465-490, 2009.

[35] G. Yukl, Leadership in Organization, Sixth Edit. New Jersey: Prentice Hall, 2006.

[36] G. Yukl, A. Gordon, and T. Taber, "A Hierarchical Taxonomy of Leadership Behavior: Integrating a Half Century of Behavior Research," Journal of Leadership \& Organizational Studies, vol. 9, no. $15,2002$.

[37] L. Woolley, A. Caza, and L. Levy, "Authentic Leadership and Follower Development: Psychological Capital, Positive Work Climate, and Gender," Journal of Leadership \& Organizational Studies, vol. 18 , no. 4, pp. 438-448, Nov. 2010.

[38] J. Barsh, M. M. Capozzi, and J. Davidson, "Leadership and innovation," The McKinsey Quarterly, no. 1 April, pp. 38-47, 2008.

[39] L. D. Mclean, “Organizational Culture's Influence on Creativity and Innovation: A Review of the Literature and Implications for Human Resource Development," Advances in Developing Human Resources, vol. 7, pp. 226, 2005.

[40] J. C. N. Valencia, R. S. Valle, and J. Daniel, "Organizational culture as determinant of product innovation," European Journal of Innovation Management, vol. 13, no. 4, pp. 466-480, 2010.

[41] S. G. Isaksen, K. J. Lauer, and G. Ekvall, "Situational Outlook Questionnaire: A Measure of the Climate for Creativity and Change," Psychological Reports, vol. 85, pp. 665-674, 1999.

[42] C. E. Shalley and J. Zhou, "Organizational Creativity Research: A Historical Overview," in Handbook of Organizational Creativity, J. Zhou and C. E. Shalley, Eds. United States: Lawrence Erlbaum Associates, 2008

[43] R. Sun and N. Wang, "Empirical Research on Organizational Climate for Innovation, Extrinsic Motivation and Employee Innovation in China," pp. 769-772, 2009.

[44] M. M. Hammond, N. L. Neff, J. L. Farr, A. R. Schwall, and X. Zhao, "Predictors of individual-level innovation at work: A meta-analysis," Psychology of Aesthetics, Creativity, and the Arts, vol. 5, no. 1, pp. 90-105, 2011.

[45] M. Goepel, "Individuals ' Support for Innovation in the Workplace A Hypothesized Model of Individual Innovation Reaction Behavior,' 2011.

[46] P. K. Ahmed, "Culture and climate for innovation," European Journal of Innovation Management, vol. 1, no. 1, pp. 30-43, 1998.
[47] M. Hassandra, M. Goudas, and S. Chroni, "Examining factors associated with intrinsic motivation in physical education: a qualitative approach," Psychology of Sport and Exercise, vol. 4, no. 3, pp. 211-223, Jul. 2003.

[48] T. M. Amabile, R. Conti, H. Coon, J. Lazenby, and M. Herron, "Assessing The Work Environment For Creativity," Academy of Management Journal, vol. 39, pp. 1154-1184, 1996.

[49] S. G. Isaksen and G. Ekvall, "Managing for Innovation: The Two Faces of Tension in Creative Climates," Creativity and Innovation Management, vol. 19, no. 2, pp. 73-88, June, 2010.

[50] N. M. Stads, G. J. Tawang, and A. Beintema, "Agricultural science and technology indicators," Agricultural Science and Technology Indicators, no. 30, 2005.

[51] J. M. Kouzes and B. Z. Posner, The Student Leadership Practices Inventory (LPI): The Facilitator's Guide, San Franchisco: Jossey-Bass Publishers, 2005.

[52] J. P. Mulki, J. F. Jaramillo, and W. B. Locander, "Critical Role of Leadership on Ethical Climate and Salesperson Behaviors," pp 125-141, 2009.

[53] G. Ekvall, "Organizational Climate for Creativity and Innovation,” pp. 105-123, 1996.

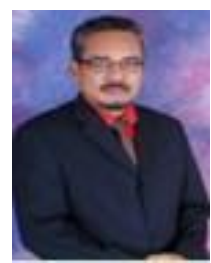

M. Noor Haris is a senior lecturer in Faculty of Technology Management and Business of Univeristy Tun Hussein Onn Malaysia, Batu Pahat, Johor. The author has earned his Bachelor (hons) degree in TESL in University Putra Malaysia. He possesed the Master of Science Technology Management in Univeristy Technology Malaysia. He is currently pursuing $\mathrm{PhD}$ in Technology Management at University Tun Hussein Onn Malaysia. He had involved various research activities focusing on SME, Technology absorption, sustainable workforce supply model, leadership and innovative work behavior. He has put much interest to explore the workforce and skill development.

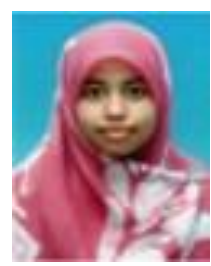

Dzulkifli Bari'ah is a post-graduate student in Faculty of Technology Management and Business of University Tun Hussein Onn Malaysia. The author has earned her Bachelor Degree (hons) in Technology Management at the same University; She is now pursuing Master of Science Technology Management in the same university. She is interested to explore applied psychology focusing on the innovative work behavior among workers, leadership practices and organizational climate in the Organization. 